\title{
A PROSTITUIÇÃO FEMININA "FECHADA" NA CIDADE DO RIO DE JANEIRO: dinâmica e organização espacial
}

\author{
“CLOSED” FEMALE PROSTITUTION IN THE CITY OF RIO DE \\ JANEIRO: dynamics and spatial organization
}

\section{LA PROSTITUCIÓN FEMENINA “CERRADA” EN LA CIUDAD DE RIO DE JANEIRO: dinámica y organización espacial}

\author{
Miguel Angelo Ribeiro \\ Universidade do Estado do Rio de Janeiro (UERJ) \\ Instituto de Geografia (IGEOG) \\ Rua São Francisco Xavier, 524, 4 andar, sala 4023 D \\ Maracanã - Rio de Janeiro, RJ - Brasil \\ CEP.: 20550-013 \\ mamikisi@gmail.com \\ Rafael da Silva Oliveira \\ Universidade Federal de Roraima (UFRR) \\ Campus do Paricarana - Bloco do Instituto de Geociências (IGeo) - Dep. de Geografia \\ Avenida Capitão Ene Garcez, 2413, bairro Aeroporto \\ Boa Vista - Roraima, RR - Brasil \\ CEP.: 69.304-000 \\ rafasolufrr@gmail.com
}

\section{Resumo}

A presente pesquisa objetiva analisar a dinâmica e a dimensão espacial da prostituição feminina "fechada" na urbe carioca, tendo por recorte temporal o final dos anos 90, do século XX, e, sobretudo, o início do século XXI, quando a mesma tornou-se bastante difundida e disseminada. Para tanto, realizou-se coleta em anúncios de jornais, de panfletos distribuídos em logradouros da Área Central, além de sites e blogs para identificação dos principais bairros, logradouros, estabelecimentos e características das profissionais do sexo, sendo complementado com pesquisas de campo realizadas entre 2004 e 2011. Sendo assim, a prostituição feminina "fechada" ganha destaque nos principais centros do país, sobretudo nas metrópoles e, no Rio de Janeiro apresenta-se distribuída por imóveis localizados em alguns logradouros da Área Central e em diferentes bairros das Zonas Sul e Oeste.

Palavras-chave: prostituição feminina; prostituição "fechada"; organização espacial; cidade do Rio de Janeiro.

\footnotetext{
Abstract

The purpose of this study was to analyze the dynamics and the geographical dimension of "closed" female prostitution in the city of Rio de Janeiro. The study makes use of data collected at the end of the 1990s, and, more significantly, at the beginning of the 21 st Century, when the activity began to spread significantly. This research is based on
} 
samples of newspaper advertisements, flyers distributed in the downtown area streets, as well as websites and blogs, in order to identify the main neighborhoods, streets and establishments involved, as well as the characteristics of the sex workers themselves. Complementary field research was also carried out between 2004 and 2011. This study indicates that "closed" female brothel prostitution has been gaining in prominence in the main urban centers in the country, especially in metropolises, and, in Rio de Janeiro, the activity is conducted on premises located in the Downtown Area and in streets of several neighborhoods in the southern and western parts of the city.

Keywords: female prostitution; "closed" prostitution; spatial organization; city of Rio de Janeiro.

\section{Resumen}

La presente investigación tiene por objetivo analizar la dinámica y la dimensión espacial de la prostitución femenina "cerrada" en la urbe carioca, teniendo por ámbito temporal, fines de los años 90, del siglo XX y, sobretodo, el inicio del siglo XXI, cuando la misma se difundió y diseminó. Para eso, se llevó a cabo la búsqueda de anuncios en periódicos, folletos distribuidos en espacios públicos de la región central, además de web sites y blogs para identificación de los principales barrios, calles, establecimientos y características de las profesionales del sexo, siendo complementado con encuestas llevadas a cabo entre 2004 y 2011. Así, la prostitución femenina "cerrada" gana destaque en los principales centros del país, especialmente en las metrópolis y, en Río de Janeiro se presenta distribuida por propiedades situadas en algunos lugares de la región central y en diferentes barrios de las Zonas Sur y Oeste.

Palabras clave: prostitución femenina; prostitución "cerrada"; organización espacial; ciudad de Río de Janeiro.

\section{Botafogo Rafaela}

Massagem profissional sobre maca contra dor muscular Stress.

Shiatsu/Sueca/Tailandesa. Local discreto aconchegante.

Domicílio. seg/sex. 2275-1468 / 9463-2078

\section{Bárbara Massoterapeuta}

Profissional sueca, tailandesa, prostática, antistress. C/ técnicas complementares. Altíssimo nível descrição, higiêne privê luxuosíssimo (cartões) 2548-1576 (Copacabana). Admite-se moças.
Rúbia T: 2524-6250. Massagista

Qualificada, técnicas sueca, taylandesa, eliminando dores, stress, dando-lhe total relaxamento. (aparelhos) ambiente discretíssimo; confira! $(40,00)$ Cinelândia www.destack.com.br/rubiate rapia 


\begin{tabular}{|c|c|c|}
\hline Centro das Massagistas & Quely (Barra) 8222-8607 & Bruna / Rose em Ipanema \\
As mais Gatas estão aqui. & Linda gata espetacular, 1.70 & massagem relaxante. Dores, \\
Local no 1 do Centro do & altura, 20ª corpo sedutor & stress, coluna, cansaço \\
Rio! Só falta você! & pele branca rosto invejável. & físico. Local tranquilo \\
Acessórios, fantasias, & Olhos verdes naturais & confortável/domicílio. \\
massagem. Tel. 2517- & cabelos lisos. Moro só. & Seg/sáb. T: $3813-1257$ / \\
1656/ 2517-1657 9 às & & $8618-3139$ \\
21h. Ac.Visa & & \\
\hline
\end{tabular}

FONTE: $O$ GLOBO, CLASSIFICADOS, 29 DE JULHO DE 2005, p.11.

\section{Considerações iniciais}

Uma das profissões mais antigas e ilegais, desenvolvida desde o aparecimento das primeiras cidades no mundo, é sem dúvida a prostituição feminina. Em se tratando do Rio de Janeiro, este segmento da prostituição ganha vulto a partir de 1850, quando as primeiras levas de imigrantes aportaram na cidade, constituídas principalmente de homens sem companheiras que influenciaram o mercado da prostituição do baixo meretrício e modificaram os costumes, a moral e o próprio ritmo da cidade (ENGEL, 1986; e MENEZES, 1992). Cumpre mencionar que, apesar de este segmento da prostituição ${ }^{1}$ persistir por mais de 160 anos na cidade do Rio de Janeiro e se difundir pelas principais cidades do país, em pesquisa divulgada pela Folha de São Paulo (1998, p.6), a atividade é considerada imoral e não deveria ser permitida segundo a maior parte dos brasileiros, mais exatamente para $64 \%$ das pessoas, no universo pesquisado, contra $29 \%$ das que a consideram um emprego como outro qualquer. Neste universo da prostituição feminina, dois tipos podem ser identificados: um mais antigo, constituído pela prostituição de rua, ocupando principalmente os logradouros da Área Central e, neste contexto, organizando verdadeiros territórios nos espaços públicos da cidade (MATTOS e RIBEIRO, 1995). Com o passar do tempo e com a própria expansão da cidade, a prostituição de rua feminina não se restringiu apenas à Área Central da metrópole carioca, apresentando um processo de descentralização, acompanhando a própria dinâmica da cidade e configurando-se em alguns bairros, a exemplo de

1 Além do segmento da prostituição feminina, Ribeiro e Mattos (1996) distinguiram o segmento da prostituição masculina, subdividido em dois grupos: o dos michês (rapazes de programa) e o dos travestis, configurando territórios em diferentes espaços públicos e privados. 
Copacabana, que a partir dos anos 1940 começa a se delinear como importante subcentro.

O outro tipo de prostituição identificado por Ribeiro e Mattos (1996, p.63) refere-se à "fechada". Ganhando vulto a partir dos anos 1980 e efetivando-se na década de 1990, esse tipo difere do primeiro, encontrado nos antigos "bordéis" da cidade. Muito embora se desenvolvendo em recintos fechados e funcionando como verdadeiros "prostíbulos modernizados", os seus serviços informais e marginalizados são oferecidos através de anúncios classificados de importantes jornais, em revistas especializadas, folhetos, folders e, principalmente, pela internet, através de sites.

Esse tipo de prostituição feminina ganha destaque nos principais centros do país, sobretudo nas metrópoles; no Rio de Janeiro, apresenta-se distribuído por imóveis localizados em diferentes bairros.

É a partir desses dados e características que a presente pesquisa objetiva analisar a prostituição feminina e a dimensão espacial desta profissão informal na cidade do Rio de Janeiro nos dias atuais (final dos anos 1990 e início do século XXI), quando a mesma tornou-se bastante difundida e disseminada em alguns de seus bairros.

Cumpre mencionar que a categoria profissão é compreendida nesta pesquisa como uma atividade ou ocupação especializada, um meio de subsistência remunerado em dinheiro ou benefícios (moradia, alimentação, roupas etc.), resultante do exercício de um trabalho (IBGE, 1999).

Neste contexto, apesar de a prostituição não ser considerada uma profissão formal no Brasil e, consequentemente, não constar na classificação dos setores das atividades econômicas identificadas pelo Instituto Brasileiro de Geografia e Estatística (IBGE, 1999), pode-se dizer que a mesma se constitui em uma ocupação remunerada pela oferta de um serviço específico: o do sexo.

Quanto à metodologia de pesquisa adotada, foram realizadas análises em anúncios de jornais, coleta de propagandas distribuídas em logradouros da Área Central, tendo-se, ainda, acessado sites e blogs para identificação dos principais bairros, logradouros, estabelecimentos e características das profissionais do sexo. Em seguida, realizou-se pesquisa de campo a partir de visitas aos diferentes estabelecimentos previamente selecionados, bem como a participação em fóruns de discussão e o exame de páginas de relacionamento direcionadas para divulgação dos locais e indicação dos 
atributos e desempenho dessas mulheres. Por fim, vale ressaltar que a pesquisa em tela é fruto de levantamento a partir de monitoramento realizado desde 2004 até o momento atual.

Destarte, para atingir o objetivo proposto, o presente artigo encontra-se estruturado em duas partes. A primeira apresentará algumas características e dinâmica da prostituição "fechada"; enquanto a segunda parte procurará analisar a distribuição espacial da prostituição na cidade do Rio de Janeiro a partir de anúncios nos classificados de importantes jornais da cidade, revistas especializadas, folhetos, folders e sites da internet.

\section{A prostituição feminina "fechada": considerações acerca de seu entendimento e dinâmica}

Como já mencionado, a prostituição feminina "fechada" é oferecida através de anúncios em diferentes mídias sob designações já conhecidas, como "termas" e "serviços de massagens". Este tipo de prostituição apresenta características distintas daquela verificada nos espaços públicos - a prostituição de rua -, a saber: quanto ao tipo de prostituta, no tocante aos atributos físicos e ao nível social; o preço (dependendo do tipo do programa) e a forma de pagamento, muitas vezes realizada através do sistema de cartão de crédito, conforme exemplificado nos anúncios expostos no início deste artigo. Tais elementos são básicos em termos de diferenciação da prostituição oferecida nos espaços públicos da cidade do Rio de Janeiro - a chamada prostituição de rua, encontrada principalmente na Área Central, na avenida Atlântica, em Copacabana (O DIA, 2002; GUELLI et al., 1996; RIBEIRO, 1997) e, mais recentemente, entre a avenida Érico Veríssimo e o início da Reserva Biológica na Barra da Tijuca (O GLOBO, 2004). Todavia, ao analisarmos pormenorizadamente o fenômeno da prostituição "fechada", percebemos que esta apresenta dinâmica complexa, assumindo nuances, ritmos e facetas, no cerne do espaço geográfico, que vão desde sua dimensão até a estruturação das redes estabelecidas. Nesse sentido, convém apontar sua subdivisão no intuito de contribuir para o entendimento acerca desse segmento da atividade sexual: i) residências; ii) termas, night clubs e casas de massagem; iii) privês e fast-sex; iv) agências de acompanhantes (FIGURA 1). 


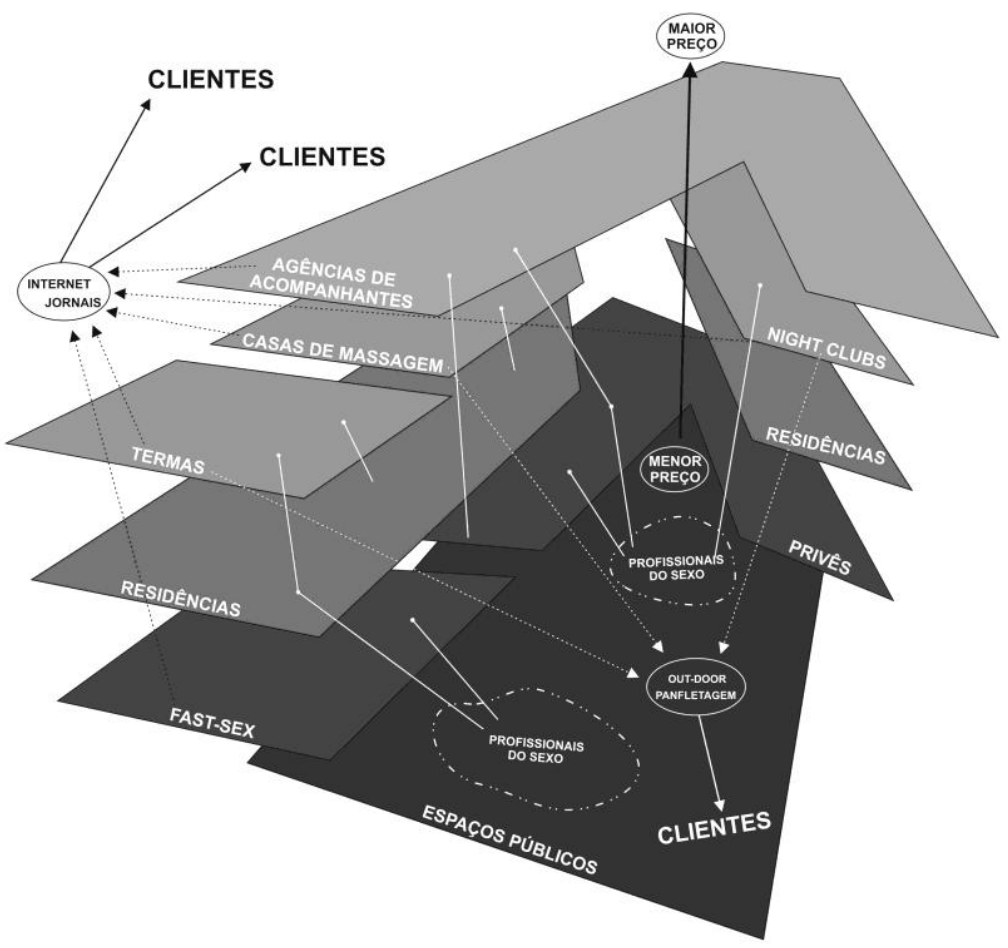

FIGURA 1: Dinâmica da prostituição "fechada" e mobilidade das garotas de programa entre os distintos circuitos.

Elaborado por Rafael da Silva Oliveira, fevereiro/2011.

Esta subdivisão da prostituição feminina "fechada" configura-se em microterritorialidades com dinâmicas diferenciadas, além de materializar redes sociais no tocante à relação cliente/profissional do sexolagenciador, componentes indissociáveis da divisão do trabalho para que esta atividade se territorialize em espaços singulares, sendo estas abordadas a seguir.

$\mathrm{Na}$ modalidade que nomeamos como "residências", algumas garotas dividem um apartamento/quitinete, cujo serviço sexual é oferecido nesta localidade ou em motéis previamente estabelecidos durante o contato telefônico (existem casos, apesar de em menor proporção, em que uma garota assume o aluguel do apartamento e realiza os serviços sexuais de maneira independente). Neste caso, as profissionais do sexo assumem as etapas que vão desde o atendimento aos clientes, por telefone, passando pelos acordos sobre horário/preço/local, além de realizarem a manutenção dos anúncios e propagandas nos classificados de jornais, sites e blogs.

Cumpre mencionar que, desde meados da década de 1990, este é o tipo de prostituição "fechada" que mais vem ganhando expressão em diversos bairros cariocas. 
Tal fato ocorre por ser o único tipo de prostituição "fechada" que possibilita a eliminação da figura do "agenciador" (popularmente conhecido como cafetão ou cáften) para trabalhar de maneira independente, ampliando assim os lucros da atividade sexual, além de evitar a exploração e os maus tratos (situação amplamente relatada pelas garotas de programa sobre a relação agenciador/profissional do sexo). Todavia, nesta modalidade também identificamos a presença de diversos agenciadores que recrutam garotas para trabalhar nesse sistema - sendo o interesse pela contratação registrado em anúncios de jornais e pela internet.

Nas termas, night clubs e casas de massagem, os estabelecimentos são mais facilmente identificados nos espaços da cidade, pois alguns possuem fachadas atraentes, além de propaganda mais ostensiva, sobrepondo-se ao simples anúncio em classificados dos jornais locais (anúncios em outdoors e panfletagem oferecendo descontos e/ou drinks cortesia nos principais logradouros da cidade, conforme indicado nas figuras $2 \mathrm{e}$ 3. Nestes "prostíbulos modernizados", com shows de striptease, oferta de bebidas e música ambiente, as relações ocorrem no próprio local, ao contrário das "residências", em que as garotas chegam a se deslocar para realizar programas sexuais em motéis. Diferentemente das "residências", as profissionais são proibidas de sair dos estabelecimentos de entretenimento durante o horário de trabalho, regras estabelecidas previamente.

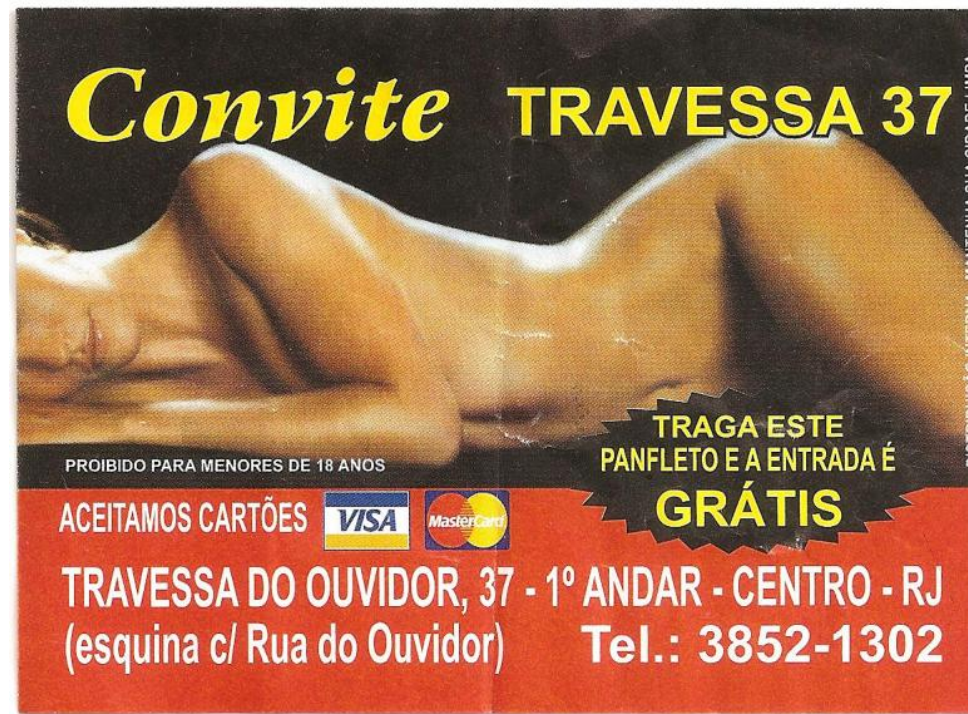

FIGURA 2: Panfleto coletado durante pesquisa de campo na Área Central do Rio de Janeiro, fevereiro de 2011. 


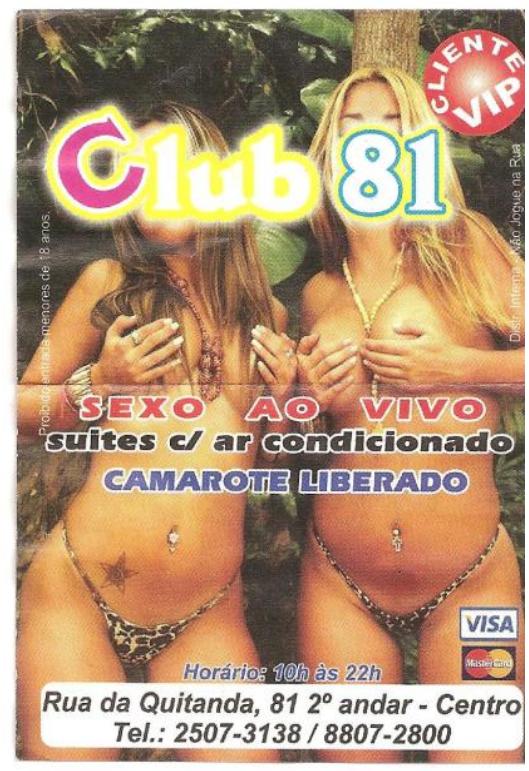

FIGURA 3: Panfleto coletado durante pesquisa de campo na Área Central do Rio de Janeiro, fevereiro de 2011.

Os privês e fast-sex são estabelecimentos situados em prédios comerciais que se apropriam de imóveis e salas, realizando adaptações nas instalações e no layout para acomodar o máximo de cabines ("quartos" improvisados para realização dos serviços sexuais) e bar. Alguns chegam a ocupar andares inteiros em endereços tradicionais da Área Central de grandes cidades, marcados pela oferta de programas rápidos (em média 30 minutos) por preços reduzidos. Tais ambientes possuem infraestrutura precária, banheiro coletivo de uso comum entre as profissionais e clientes, além da ausência de controle sanitário e higiene. Tais motivos, aliados à clientela de baixo poder aquisitivo e à alta rotatividade dos estabelecimentos, contribuem para que esses espaços da prostituição "fechada" sejam conhecidos pelos seus frequentadores como trash.

Vale destacar que o acesso às termas, aos night clubs, aos privês e às fast-sex não está condicionado de imediato à efetivação dos acordos sexuais, pois essas modalidades da prostituição "fechada" oferecem outros serviços, tais como pista de dança, open bar, jogos e exibição de shows performáticos.

Por fim, as agências de acompanhantes são compostas por um escritório voltado para a oferta de diversas garotas de programa, abarcando as mais variadas exigências dos clientes (desde atributos físicos - como morenas, negras, orientais etc. -, passando pelo registro do nível de escolaridade, preferências e características da personalidade, até mesmo fluência em idiomas - além de fantasias sexuais). Sua divulgação ocorre 
majoritariamente através da internet, em páginas especializadas, e de anúncios em jornais locais. Voltados para um público de maior poder aquisitivo (principalmente turistas), em meio ao perfil de diversas acompanhantes, é possível identificar informações atreladas ao currículo profissional, como, por exemplo, os atributos de modelo, atriz pornô e capa de revistas masculinas (Sexy, Private, entre outras). Devido à expansão deste tipo de modalidade nos últimos anos, vem crescendo o número de sites especializados em divulgar contatos, perfis e fotos de profissionais independentes, em que as mesmas pagam uma taxa mensal pelo serviço de divulgação na rede. Assim sendo, é comum encontrarmos a mesma garota sendo anunciada em diversos sites especializados, com nome, preço e idade diferentes.

A organização desses verdadeiros "prostíbulos modernizados" está relacionada a uma série de fatores; dentre eles, à própria modernização tecnológica, dos costumes e da sociedade. A tendência foi a de que as profissionais do sexo também reorganizassem o perfil da atividade, inicialmente com pagers e, atualmente, com celulares e contato via internet, não recorrendo a cafetões, tornando-se, muitas vezes, autônomas e chegando a ganhar até 67 salários mínimos mensais (TRINDADE, 1997, p.46). Este modelo de prostituição fez com que as novas profissionais do sexo se intitulassem garotas de programa, acompanhantes para executivos ou call-girls, sendo o estigma de prostituta substituído por tais denominações. Segundo Trindade apud Fonseca (1997, p.46), referindo-se ao segmento mais moderno da prostituição feminina, "a prostituição é um bico, uma forma de complementar a renda familiar, o que as faz levar uma vida dupla e a não se assumir como prostitutas".

Todavia, da mesma forma que surgiram novas possibilidades para desempenhar o trabalho sexual de maneira independente, os agenciadores se adaptaram à nova realidade; e, no momento atual, em todos os segmentos da prostituição, tanto nos espaços públicos quanto nos circuitos "fechados", eles se fazem presentes, substituindo a figura do cafetão pela autodefinição de "empresários".

Outro fator significativo da prostituição 'fechada' diz respeito à oferta dos serviços sexuais que ocorre durante as 24 horas do dia, ao contrário daquela praticada nos espaços públicos, cuja fluidez cíclica e temporal favorece a expansão/contração ao longo do dia, chegando a desaparecer por completo em determinados logradouros e horários específicos (SOUZA, 1995). Tal situação contribui para que diversas "garotas 
da pista", ou seja, que trabalham nos espaços públicos, também façam anúncios nos jornais e em blogs na internet, atuando assim nos dois segmentos do serviço sexual (FIGURA 4).

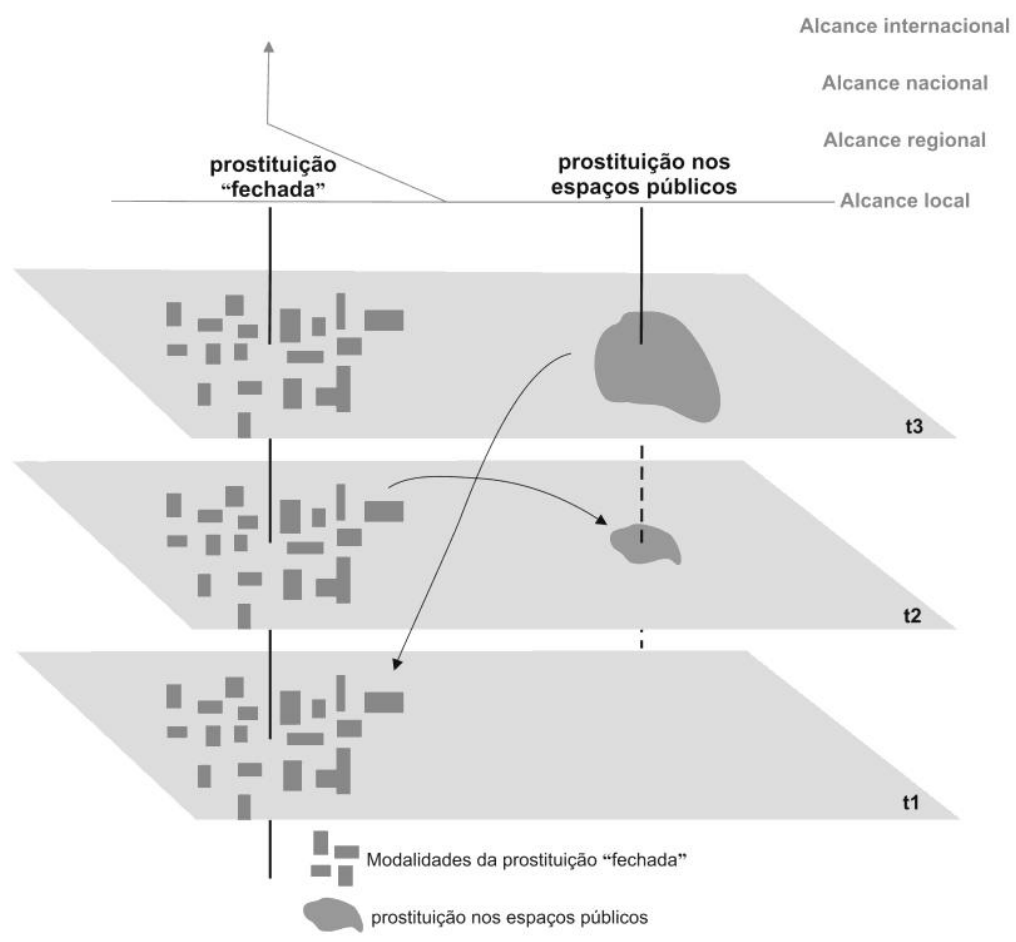

FIGURA 04: Alcance espacial da prostituição feminina "fechada" e nos espaços públicos: um esquema hipotético.

Elaborado por Rafael da Silva Oliveira, fevereiro/2011.

Entrevistando algumas profissionais do sexo, é comum registrar que uma mesma garota veicula diversos anúncios em jornais e sites com nomes, perfis e preços distintos, com o intuito de atingir o máximo de clientes interessados por esse tipo de serviço. Convém destacar que algumas, que atendem em casa e nos motéis, também atuam em logradouros da cidade, apesar do trabalho "na pista" ser sempre associado a ganhos menores nos programas sexuais. Tal situação não ocorre com as mulheres que moram nos night clubs, termas e casas de massagem, pois, como a maioria reside onde trabalha, não possui o direito de trabalhar em outro lugar (e, tampouco, em outra modalidade da prostituição "fechada"). 


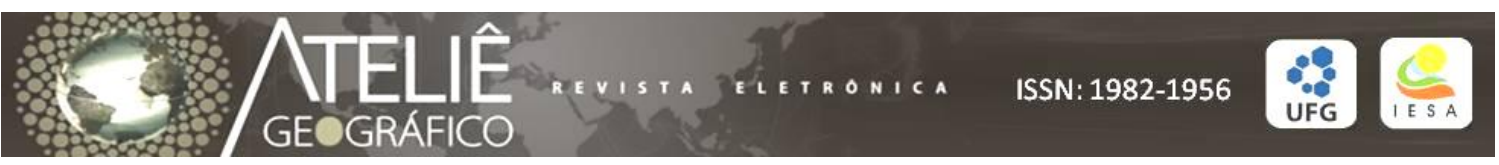

Tendo apresentado as considerações acerca da prostituição feminina "fechada", na próxima etapa de análise passaremos a tratar da distribuição espacial desse segmento.

\section{Prostituição feminina "fechada": uma análise espacial}

$\mathrm{Na}$ análise espacial da prostituição feminina "fechada", a partir das diferentes modalidades identificadas e caracterizadas no quadro 1, podemos distinguir as áreas de maior atuação da referida atividade.

As termas, casas de massagem e night clubs estão confinadas em determinados fixos (imóveis) localizados em logradouros, principalmente na Área Central (Termas 65, Quatro por Quatro) e no bairro de Copacabana (Monte Carlo e L'uomo Club). Cumpre mencionar que os night clubs estão localizados tradicionalmente no bairro de Copacabana, concentrados na avenida Princesa Isabel e arredores, destacando-se o Café Sensoo, a Boate Frank’s Bar, La Cicciolina e a Barbarella.

De modo geral, a localização dos fixos supramencionados está relacionada, entre outros fatores, à própria deterioração da função comercial e/ou residencial de alguns prédios, vinculados a uma mudança de seus conteúdos sociais; além da clientela em potencial que transita por esses espaços. Todavia, há casas de massagem e termas de alto padrão caracterizadas como luxuosas, sendo estas localizadas em bairros como Ipanema (Centaurus), Jardim Botânico (Solarium) e Recreio dos Bandeirantes (Âncora do Recreio).

No que concerne aos privês e fast-sex, a significativa maioria localiza-se na Área Central, com presença nas ruas do Ouvidor, Carioca, Buenos Aires, Uruguaiana e nas avenidas Rio Branco, 13 de Maio e Presidente Vargas; destacando-se: Cléo Massagens, Bel Prazer Massagens, Centro Star, Danuza Pinheiro, Bia Massagens, Delírio G e Bellas Massagens, dentre outras. Este tipo de estabelecimento também é identificado no bairro da Tijuca com as Tigresas Tijucanas e TM Studio.

Essas modalidades da prostituição feminina funcionam sob as denominações de termas, saunas, casas de banho, academias de ginástica, centros de lazer, cabeleireiros etc. Como indicado em matéria publicada no jornal $O$ Globo (2001, p.17): "com esses nomes, as casas de prostituição no Rio conseguiram registros em cartórios na Junta Comercial e licenciamento da prefeitura sob a fachada de prestação de seus serviços 
legais". Para escapar de um processo criminal, segundo a Legislação brasileira, os proprietários de alguns desses estabelecimentos de prostituição burlam a fiscalização, mudando a razão social em alterações contratuais que indicam o verdadeiro ofício. No caso da oferta de serviços sexuais do tipo "residencial", a atividade, em sua maioria, ocorre de forma "clandestina", pois um agenciador ou um grupo de garotas de programa aluga o apartamento/quitinete e anuncia nos jornais e internet sem nenhum registro ou licenciamento para desempenhar tais atividades.

As "residências" estão situadas em diversos bairros da cidade, cuja maioria encontra-se em Copacabana, Tijuca, Barra da Tijuca, Recreio dos Bandeirantes, Ipanema, Leblon, Flamengo e Botafogo. Vale ressaltar que essa modalidade predomina em Copacabana por apresentar o maior número de imóveis com presença desse serviço, quando comparado à Área Central e demais bairros cariocas, sobretudo em relação ao número de apartamentos/quitinetes, alugados como residência, que são utilizados para a oferta desses serviços. Tal fato pode ser explicado segundo diferentes fatores; entre eles, em decorrência da existência de imóveis com pequenas dimensões - caso, sobretudo, das quitinetes -, além da presença de turistas que procuram esse serviço; mas também em decorrência da maior deterioração de alguns prédios e menor sindicância quanto ao tipo de morador, permitindo, de certa forma, essa prática. Na realidade, a prostituição feminina, nesse bairro, aparece espacializada, sobretudo em imóveis localizados nos seguintes logradouros: avenidas Nossa Senhora de Copacabana, Prado Júnior, Princesa Isabel e ruas Barata Ribeiro, Figueiredo Magalhães, Siqueira Campos, Ministro Viveiros de Castro e Hilário de Gouveia.

Ao analisarmos os sites de agências de acompanhantes ${ }^{2}$ na oferta da prostituição feminina, podemos constatar que a distribuição espacial se faz presente na Zona Oeste, destacando-se com maior intensidade na Barra da Tijuca, Recreio dos Bandeirantes e Jacarepaguá; secundada pela Zona Sul, ressaltando Copacabana, Ipanema, Botafogo e Flamengo; na Área Central e Zona Norte, principalmente no bairro da Tijuca.

Na Área Central, existem alguns logradouros - como Senador Dantas, Sacadura Cabral, "Cinelândia" (Praça Floriano), Senado, Joaquim Silva, entre outros - que concentram hotéis/apartamentos associados a esta atividade. Já em Copacabana, a rua

2 Foram pesquisados 11 sites, a saber: Gostosuras de Luxo, Rio Sexsite, Nitclub, Ellitério, Donas do Luxo, Gatas Endiabradas, Barra Vips, Scort Rio, Vip Rio de Janeiro, Lovers Rio e Cama Quente. 
Barata Ribeiro e a avenida Nossa Senhora de Copacabana evidenciam-se como importantes locais, com grande presença de imóveis para a prática desta atividade.

Ao final dos anos 1990 e início do século XXI, constatou-se que a prostituição "fechada" apresentou um processo de descentralização, em direção a bairros das zonas Norte e Oeste da cidade do Rio de Janeiro, destacando-se: Tijuca, Méier, Madureira, Jacarepaguá e principalmente a Barra da Tijuca, nos quais este tipo de serviço começa a ocupar imóveis localizados em seus logradouros. Nos últimos anos, a Barra da Tijuca e o Recreio dos Bandeirantes - juntamente com Copacabana - têm registrado a expansão, cada vez maior, da presença de agências de acompanhantes de luxo, em decorrência do quantitativo de hotéis, flats e apartamentos para temporada.

Este tipo de prostituição acompanha as próprias transformações do processo socioeconômico organizado nos grandes centros urbanos do país, mais precisamente nas metrópoles. Trata-se de uma atividade que, apesar de informal, em decorrência de ser considerada marginal pela sociedade e pela legislação vigente, vincula-se também ao setor formal, em função de uma série de relações que vão se estruturando, caso de anúncios via jornais e internet; aceitação de cartão de crédito para pagamento; aluguel de imóvel, muitas vezes, veiculado sob o rótulo de "para temporada", entre outros. Alguns funcionam como verdadeiras agências, com um responsável que geralmente controla vários imóveis com grupos de prostitutas, atuando como verdadeiros "cafetões ou cafetinas" modernizados, assumindo o papel de pequenos empresários capitalistas ${ }^{3}$.

Sendo assim, há uma mudança do conteúdo dos espaços fechados, fazendo com que uma nova forma de trabalho, concernente aos serviços sexuais, seja oferecida na cidade, inserindo outras funções e relações na organização do espaço urbano.

\section{Considerações finais}

A prostituição feminina "fechada" apresenta especificidades quando se analisa a sua prática nos espaços privados. Este tipo de prostituição ganha destaque, a partir dos anos 1980, quando timidamente começa a ser anunciada nas páginas dos cadernos classificados dos principais jornais da cidade, como uma das resultantes da abertura política e democrática do país e do afrouxamento dos ditames da censura oficial, 
tornando possível a emergência desta "nova" modalidade de trabalho - a prostituição "fechada", que a partir dos anos 1990 é oferecida, também, através da internet, conduzindo os clientes que a acessam, em busca dos serviços do prazer, a entrar em contato com esses espaços privados.

Neste sentido, no momento atual, não se pode ocultar o fenômeno da prostituição e sua dimensão espacial, pois essa atividade é um elemento da produção do espaço, concretizada pelos clientes/prostitutas e outros, que são os agentes modeladores desse espaço, organizando verdadeiras redes do sexo. Sendo assim, para a Geografia, mais um campo fértil se delineia para pesquisas referentes à dimensão espacial deste fenômeno nas cidades brasileiras. Fenômeno que se difunde pelos espaços da cidade do Rio de Janeiro, organizando esta forma de trabalho que, apesar de antiga, reestruturouse, acompanhando a própria modernização tecnológica, dos costumes e da sociedade.

\section{Referências}

ENGEL, Magali G. A cidade, as prostitutas e os médicos. Revista do Rio de Janeiro, Niterói, vol. 1, no 3, p.31-39, maio-agosto de 1986.

FOLHA DE SÃO PAULO. $5^{\circ}$ Caderno Mais! O relatório folha da sexualidade brasileira. São Paulo. 1998, p. 6.

GUELLI, Lívia Maria et al. Avenida Atlântica. Comunicação e Cultura. UERJ. (mimeo). 1996.

IBGE. Pesquisa Nacional por Amostra de Domicílios. Rio de Janeiro, v. 21, 1999, pp. 1-113.

MATTOS, Rogério Botelho de; RIBEIRO, Miguel Angelo Campos. Territórios da prostituição nos espaços públicos da área central do Rio de Janeiro. Boletim Goiano de Geografia, vol. 15, n 1, p.57-79, janeiro-dezembro de 1995.

MENEZES, Lená Medeiros de. Os estrangeiros e o comércio do prazer nas ruas do Rio (1890-1930). Rio de Janeiro: Arquivo Nacional. 1992, 117 p.

O DIA. 07.04.2002, p.3

O GLOBO. Classificados. 29.07.2005, p.11.

Rio. 05.09.2004, p.24

3 O filme $O$ diabo a quatro, de Alice de Andrade, aborda este fenômeno no bairro de Copacabana. 
Rio. 22.04.2001, p.17

RIBEIRO, Miguel Angelo; MATTOS, Rogério Botelho de. Territórios da prostituição nos espaços públicos da área central do Rio de Janeiro. Território, Rio de Janeiro, vol. I, $\mathrm{n}^{\mathrm{o}} 1$, p.59-76, julho-dezembro de 1996.

RIBEIRO, Miguel Angelo. Prostituição de rua e turismo em Copacabana - a Avenida Atlântica e a procura do prazer. Território, Rio de Janeiro, ano III, n 3, p. 87-99, julhodezembro de 1997.

SOUZA, Marcelo Lopes de. O território. Sobre espaço e poder, autonomia e desenvolvimento. In: CASTRO, Iná Elias de; GOMES, Paulo César da Costa; CORREA, Roberto Lobato (orgs.). Geografia: conceitos e temas. Rio de Janeiro: Bertrand Brasil. 1995, p.140-164.

TRINDADE, Eliane. Microempresárias do sexo. Isto É. São Paulo, nº 1464. Outubro de 1997. p.46-53.

Recebido para publicação em fevereiro de 2011 Aprovado para publicação em maio de 2011 